Article

\title{
Renewable Energy, Ecology and Environment to Arabic Pupils Using a Creative, "Hands On" Approach
}

\author{
Hen Friman ${ }^{1, *}$, Yafa Sitbon ${ }^{2}$, Ifaa Banner ${ }^{2}$, Tal Shauli ${ }^{3}$ and Yulia Einav ${ }^{1,2}$ \\ 1 Faculty of Engineering, HIT_Holon Institute of Technology, Holon 5810201, Israel; yulia_e@hit.ac.il \\ 2 Dean of Students Office, HIT—Holon Institute of Technology, Holon 5810201, Israel; yafasit@hit.ac.il (Y.S.); \\ ifaab@hit.ac.il (I.B.) \\ 3 Faculty of Design, HIT—Holon Institute of Technology, Holon 5810201, Israel; talshauli@yahoo.com \\ * Correspondence: henf@hit.ac.il; Tel.: +972-3-502-6695
}

Received: 15 April 2018; Accepted: 3 June 2018; Published: 4 June 2018

\begin{abstract}
An action learning course is an academic course which involves academic learning and social activities, and has an impact on the community. In the last year, students from the HIT, Holon Institute of Technology, participated in the action learning course "Green Ambassador", which aimed to teach pupils about renewable energy and preserving an environment. As part of the course requirements, students were asked to conduct enjoyable lessons for fifth and sixth grade pupils in the Arabic elementary school "Alomaria" situated in the city of Ramle. During lessons held within the school, the students taught the pupils via games and activities what is soil contamination, how to turn waste into a resource, what is an air pollution, energy conversion and etc. In order to illustrate the topics studied by the pupils, the students used a moveable laboratory containing demonstrations, experiments and creative activities. Thus, active participation of the pupils in the lessons was achieved. The results show higher rates of success in the final questionnaires on the lessons' topics and involvement, due to an enriching and a challenging experience of learning. Thanks to the action learning course, the pupils became more aware and learned an important lesson about the ways to preserve the environment.
\end{abstract}

Keywords: Arabic; environmental education; elementary school; Hebrew; Green Ambassador; renewable energy

\section{Introduction}

Creating a clean energy future is one of the worldwide goals in 2018. For now, world energy consumption relies heavily on fossil fuels, which are non-renewable and eventually finite, such as coal, oil, and natural gas. These resources already become too expensive or too environmentally damaging to retrieve. The importance of renewable energy and energy efficiency technologies is constitutively rising. Wind and solar energy are the examples of renewable energy resources that are constantly replenished and will never run out [1,2].

The last decades have been dominated by the rapid changes introduced by the technology revolution, which has a tremendous influence on our daily lives. Today we are facing a myriad of new challenges. Technology-based industry has matured in many ways and the required skills for future engineers are much more complex in a world where "machines/computers" execute many of the engineering tasks. Most of all, we are facing a new generation of sophisticated students, who were born into the digitized/multimedia world. One of the missions of the academic world is to encourage and initiate the development of new study programs and methods, while being responsive to the rapidly changing trends in the field. The proper education of the undergraduate students must 
also be a function of market needs and predictions of how technology will develop in the foreseeable future. In order to ensure that our graduates are well qualified to meet the future needs of the market, meticulous attention must be paid to maintain a high standard in the fundamental courses and impart practical tools and skills. It is also important to introduce a wide variety of new subjects to the academic curricula.

Holon Institute of Technology ("HIT") developed a new renewable energy academic program in order to educate professionals with a background and understanding in the field. This program runs at the Faculty of Electrical Engineering and it provides the students technical and practical aspects of energy use and energy efficiency [3].

As part of this institutional trend, the course "Green Ambassador" was developed. This course integrates social involvement program run by the Dean of Students Office and the "Israeli Hope in the academia" national program, in which HIT is participating. Among the goals of the course are making the ecological and environmental issues knowledge accessible to the pupils themselves and to the community, bringing to light the importance of keeping the quality of the environment and educating the next generation about basic energy efficiency.

2017-2018 academic year course was in a collaboration with an Arab community school "Alomaria" located in Ramle. Six groups of three to five students and pupils from six classes, fifth and sixth graders (total 164 pupils), participated in this course. The collaboration between the students (25 students from various faculties and departments in HIT) and the HIT staff and the pupils and school staff was excellent and beyond reaching the course's goals of producing knowledge, skills and vision of energetic efficiency, the course contributed to the feeling of closeness and mediation between the Jewish and the Arab community. As described in previous research, Jewish and Arab work together for shared goal increased closeness and mediation [4].

Throughout the course, which lasted for one semester during October 2017-January 2018, the HIT students conducted 90 min lessons. Each lesson dealt with another important aspect of meaningful environmental issues. The pupils were given examples how to save energy by simple daily actions such as turning off the light when leaving the room and opening the shutters at day time. The lessons passed in a most enjoyable way. At the beginning of each meeting there was a quiz whose purpose was to check the children's initial knowledge of the topic. They got practical experience by the moveable lab which contained a number of demonstrating kits in various subjects: renewable energy, air pollution, waste and recycling, soil contamination and energy efficiency. On every team a group of students had been responsible who studied the topic thoroughly and prepared lesson plans. Finally, the concluding questionnaire was administered which checked the pupils' level of knowledge after the activity. The children turn into more aware in protecting the environment in which they live. The students passed on their knowledge about environmental damage and waste of energy. The key purpose of the course-training "Green Ambassador" from a young age, was achieved. We believe that academic courses such as the one we are reporting here, will minimize environmental damage and increase the global consciousness.

\section{Holon Institute of Technology}

The HIT_-Holon Institute of Technology—was established in 1969 and became an independent public academic institution of higher education in 1999, certified by the Council of Higher Education of Israel. HIT focuses on the teaching of sciences, engineering, computer science and technology, management of technology and design. It also emphasizes multi-disciplinary theoretical and practical research of innovative technologies from a professional scientific, economic and cultural perspective. HIT trains highly qualified students in the realms of science, engineering, management and design, and plays an important role in their integration upon graduation into key positions within the industry. HIT aspires to achieve quality and excellence in teaching and innovative research, and strives to introduce novel and unique cutting-edge teaching and research technologies. HIT also prides itself on its advanced academic achievements, application of innovative techniques and interdisciplinary 
professionalism that lead to creative teaching and new technologies. HIT aims to utilize the intellectual and professional potential of each and every student, so that they can fully integrate into the fast-paced technological world of today. Providing superior technological and scientific education enables HIT graduates to enter key leadership positions in both the private and public sectors.

\subsection{Faculty of Engineering}

The aims and goals of the Faculty of Engineering are to keep the study programs updated to meet the ever-changing requirements for engineers of the future, enrich the student's theoretical knowledge as well as teach practical and design skills and knowledge; provide the students with a rich and comprehensive study program; adapt teaching methodologies and techniques, focusing on understanding as a goal; enable students to achieve skills such as self-learning and to acquire expertise via practice; constantly update the teaching methods and the study programs; maintain relationships with the various relevant industry sectors; introduce the students to state-of-the-art equipment and facilities; promote research in the various fields and explore cooperation with other institutes in Israel and abroad.

\subsection{Social Involvement Unit at the Dean of Students Office}

One of the many goals of the Social Involvement Unit is to promote social involvement of students and staff in the community. It also promotes under-represented populations at the institute by offering mentoring, tutoring, emotional support, guidance to learning and adjustment to the academic world. Over the years, the unit has worked in many education and welfare arenas to promote immigrants, youth, and more. The Social Involvement Unit serves as a professional center to encourage and promote the social impact of students and staff and to leverage knowledge, expertise, and human capital for the benefit of the community through social involvement projects and course actions involving meaningful activities.

\subsubsection{Action Learning Course}

The action learning course is an academic course which involves academic learning and social activities. The courses deal with processes and social challenges, reveal different ideologies, and develop critical thinking and pragmatic ideas. Students receive course credits and a grade for being part of such courses. Participating students enroll in courses that involve action and activities to engage in the experiential learning process, thereby creating a dialogue and cross-fertilization between being taught in the classroom, and the experience of reality in the real world [5]. A learning experience includes meeting with social organizations, institutions, and state authorities and carrying out practical work with diverse populations. Through experience, students strengthen their academic skills, formulate ethical attitudes toward reality, develop professional and civilian perspectives, and realize how they can influence their surrounding in the present and the hereafter. HIT's students engaged in an action learning course created a dialogue and cross-fertilization between what was being studied in the classroom and reality. Reddan and Rauchle (2012) found in their study that through the experience, the students strengthened their academic skills and values, formulated ethical attitudes toward reality, developed a professional and civilian approach [6].

\subsection{2. "Green Ambassadors" in the Community Course}

Under the guidance and supervision of Dr. Hen Friman, The Holon Institute of Technology has set up an innovative course which puts together learning of students in the classroom and social doing-passing on material they have learnt to elementary pupils in an enjoyable way to boost awareness and accessibility to knowledge and information regarding environmentalism. The ultimate goal was that the young pupils would become "Green Ambassador"—children with environmental awareness. In the frontal part of the course, students got an introduction to the Arabic society and acquired knowledge on environmental issues, such as ecology, electricity production, air pollution, renewable 
energy, water sector, waste and recycling. The students learnt how an effective and enjoyable method of teaching is based on the knowledge acquired and were divided into working groups. In the practical part of the course (October-November, each group planned, purchased and built samples and formed a teaching model exemplifying one scientific doctrine studied in the course. The students presented these enjoyable workshops to the fifth and sixth graders "Alomaria" Ramle school (November-January). Throughout the whole process efficiency test were taken. Every meeting the pupils were asked to answer a questionnaire related to issues learnt in class. In the beginning of the activity an opening questionnaire was passed on. The purpose was to know what the basic level of the pupils was. At the end of the activity a final questionnaire was delivered which indicated the progress and the knowledge acquired as a result of the activity. The questionnaire was presented to the pupils as a trivia game program.

\section{Educational Aspects}

The educational landscape is changing and, in this context, life skills are increasingly mentioned as relevant skills that pupils and adolescents should learn. The small portfolio of studies suggests that life skills of adolescents can be strengthened through experience and education programs [7].

The overall purpose of the course has been to raise the awareness of environmental issues among the pupils, boost their affinity towards the importance of the subject, give them practical tools to preserve the environment and for energetic efficiency. Thus make them pass on the knowledge acquired to their surroundings, the Arab society at large, the country and the world.

In this article we describe two education aspects as a part of the course methodology:

1. Describe the content of the course and how the knowledge obtained was passed on to young pupils using a creative, "hands on" approach which was believed to be more effective than traditional teaching methods in helping young pupils to internalize knowledge learned in the classroom.

2. Show how successful the entire program was by assessing not only their own success in teaching others and the benefits obtained from this experience but also by assessing how much knowledge the pupils retained from these classes.

Walker and Jorn (2009) found in their study that although pupils wanted to use technology, they also wanted to retain face-to-face instruction and interaction with their staff [7]. However, research states that lecturing as a type of face-to-face instructional technique, especially in a writing classroom, is one of the least effective teaching methods to motivating pupils [8,9]. "Hands on" learning has gained a greater foothold in the classroom as researchers have documented what teachers have long understood: pupils become more engaged in learning when they have a chance to dig into complex, challenging, and sometimes even messy problems that closely resemble real life [10]. Brain research underscores the value of these learning activities and pupils' abilities to acquire new understanding [11]. A "hands on" approach put pupils in an active role such as: problem solver, decision maker, investigator, or documentarian. Shulman and Tamir (1973) have been proposed that "hands on" increase student achievement in science education. A set of theories has been proposed to explain how hands-on science benefits student learning of science [12].

The students, in their part, learnt much from the pupils and the school's staff and got to know better the Arab society and its leaders, according to interviews. The interviews were conducted with the students at the end of the course. Brown (1992) found how examples and analogies can help student to remediate misconceptions in physics [13]. We show how games and activities together, Jewish and Arab for shared goal increased closeness and mediation

The course methodology included "mutual fertilization"; the pupils acquired knowledge while the students got familiar with the Arab society in an informal and unprejudiced way (Figure 1). There are several cases that described how Jewish and Arab teamwork increased exposure, closeness and mediation $[4,14]$. 


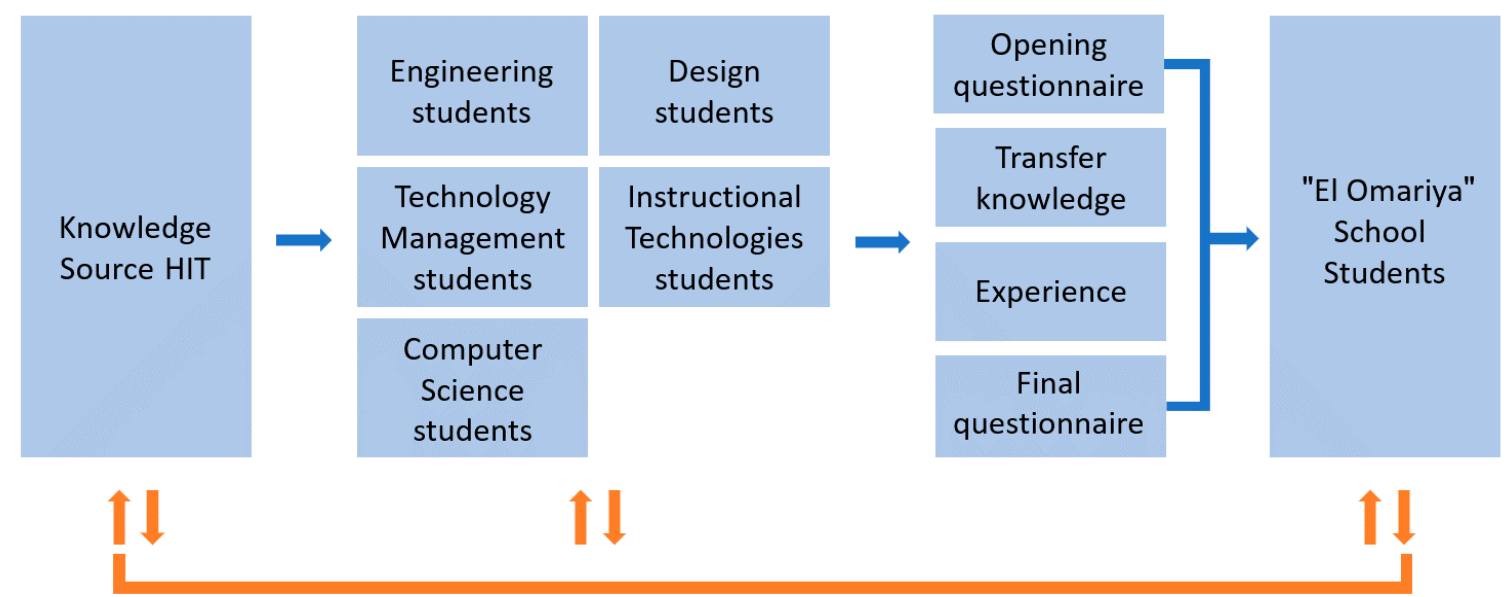

Knowledge Transition orbit

Acquaintance between societies in Israel orbit

Figure 1. The course "Green Ambassador" approach that included mutual fertilization between the students and the pupils, in which the students got familiar with the Arabic society and passed their environmental knowledge to the pupils.

All the groups have taken an opening and final questionnaire every meeting in order to check the change in knowledge and hence the efficiency of the course. All the groups conducted theoretical knowledge lessons accompanied by a presentation including pictures and videos illustrating the material as well as an enjoyable and significant part which also comprised of performing scientific experiments in class so as the pupils would internalize the material. Throughout the activity, the students helped raise the motivation among the pupils. Even with the quietest pupils were encouraged to ask questions and take an active part in the lesson. Of the 164 pupils in fifth and sixth grades in "Alomaria" school, only 7 pupils (less than 5\%) refused to participate in the experiments and the creative activities. Every pupil was motivated to prove himself. Brown (1992) and Yage (1995) in previous research, describe that experience and challenge encourage engagement, participation and learning $[15,16]$. The results in all the classes and among all the groups were highly positive. The pupils understood the purpose of the course and the importance of the issues studied. Based on the responses from pupils and teachers at the end of the activity, the students learned that the pupils are interested in preserving the environment and making a better future for everyone and also to become ambassadors of preserving the environment even by doing a small things, which turn to be so meaningful, like not leaving garbage on a picnic and turning the lights off when leaving the room. As a result, pupils had become aware and confident of their ability to make a significant and a positive change.

\subsection{Renewable Energy}

The Ministry of Energy and Water works to develop and integrate renewable energy in the Israel's economy. This is the effect of a governmental decision regarding the issue whose goal has been to promote energy confidence and independence and reinforce environmental aspects. In Israel and worldwide awareness and encouragement have been raised to stress the importance and exchange to renewable energy- energy whose origin is solar radiation, wind biomass and other resources which are neither biodegradable nor fossil fuel. The group which engaged in "renewable energy" set itself a goal to present the pupils the possibility to produce energy in those ways which are not polluting the environment. Throughout the activity the pupils learned about various types of renewable energy via a 
memory game (flashcards and pictures) (Figure 2a), the students carried out an experiment simulating "the Ozone Hole" — dwindling the ozone layer which is $25 \mathrm{~km}$ above earth [16,17]. This is caused by the emission of pollutants. In order to integrate all the pupils and make the activity competitive, the pupils were required to divide into groups, each one had to start a solar vehicle by a moveable light source (Figure $2 b, c)$. Thus a solar car race was run in class.

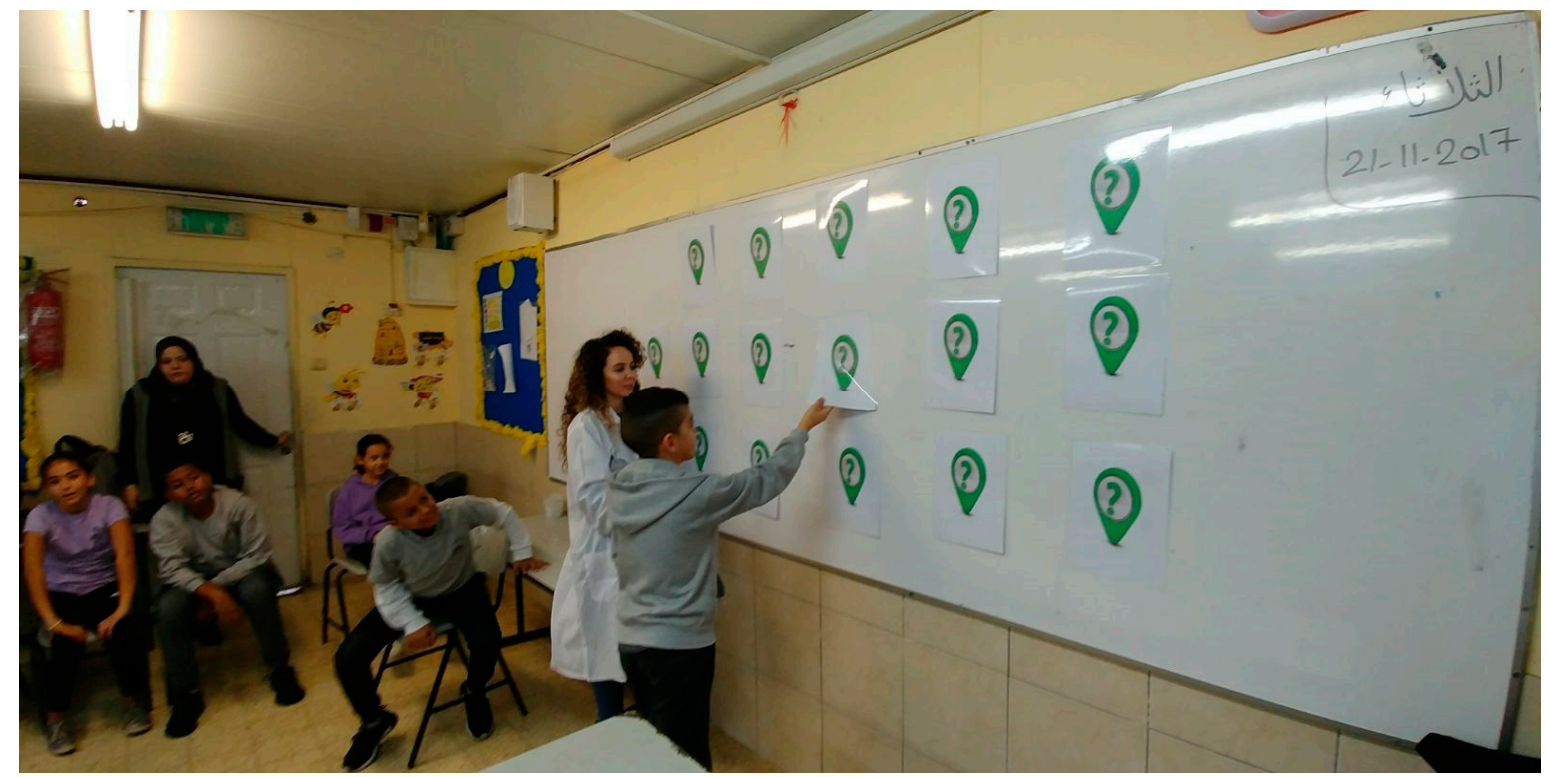

(a)

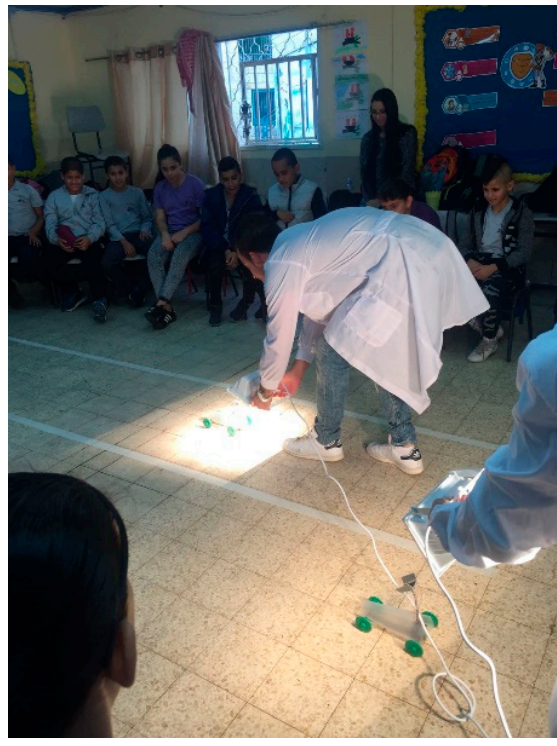

(b)

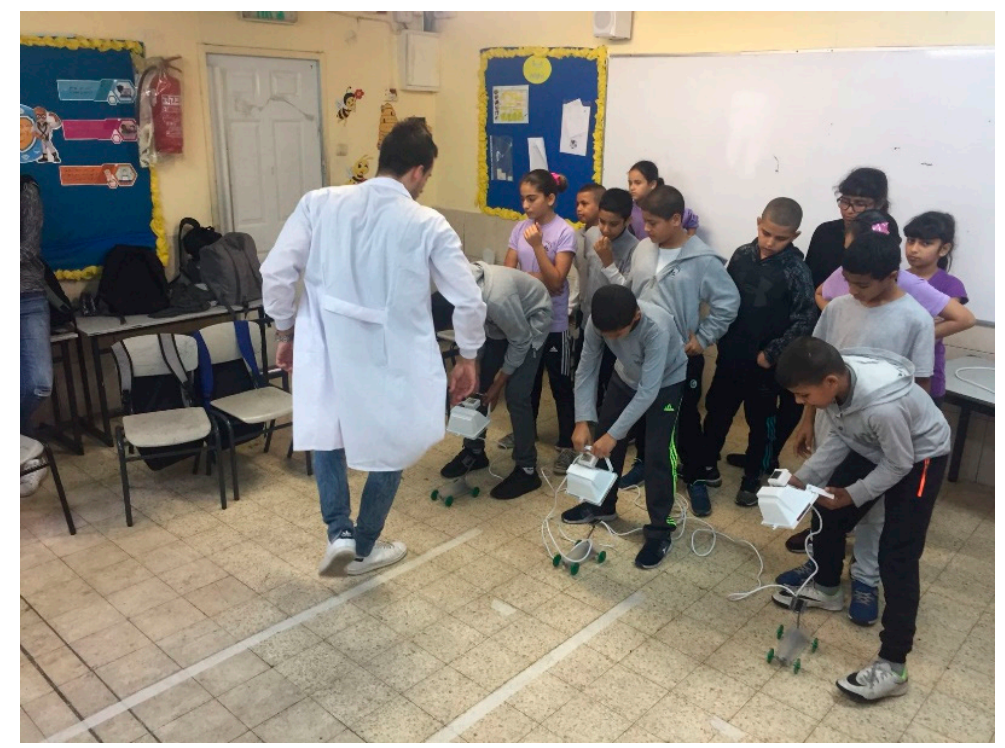

(c)

Figure 2. (a) Memory game about types of energy presented by the "Renewable energy group"; (b,c) Solar class race. The pupils were asked to start them by a moveable light source.

\subsection{Energy Efficiency}

The course dealt, among other things, the capacity to produce electricity existing in Israel which does not meet the growing demand. The State of Israel suffers from lack of electricity which is expressed mainly at the peak hours in the morning in summer and winter. Unless action is taken immediately, a crisis is expected that in the coming years which may disrupt the economic activity 
and the residents' life. Energy efficiency is a vital step in reducing the energy consumption in general and that of electricity, in particular. Energy efficiency groups set themselves a goal to expose the young pupils to this issue and give them practical tools for energy efficiency $[17,18]$. In addition, these organizations strive to make the pupils understand that each of them can contribute to himself and to the surrounding by making simple changes. In the course of the class activity the students showed the pupils physical examples of more and less economical products. Prior to the explanation and afterwards, the children were asked which ones they thought were more economical in energy. Also, the children were asked to experiment boiling water for tea or coffee in a kettle. While the activity was carried out the question asked was: how much water should be filled in the kettle? What is the right amount, one glass, two glasses, half of the kettle or a full kettle. The students showed the pupils visually that the more water filled in the kettle, the longer it takes to boil the water. Thus, the energy consumption grows and so does the electricity bill. Therefore, the pupils learnt the kettle should be filled only up to the desired amount.

\subsection{Air Pollution}

Producing energy from mineral sources such as coal, oil and even natural gas pollute the air because of the emission of pollutant to the atmosphere. The group of students who faced air pollution presented how the burning process of an organic material (just like coal and oil) produces energy however, it also emits pollutants. The students showed the pupils a "friendly way" for the environment to prepare ice cream with no need of a machine or freezer which consume energy. The pupils prepared and ate their own ice cream which there was no air pollution, because of that in the preparatory process does not require electrical energy.

\subsection{Water Pollution}

The course dealt with another issue which is water sector- water is the most basic product for life. Managing the national water sector facing the lack of the resource sets complexed challenges requiring the best response. The state of Israel is located in an area which suffers from lack of water. Despite this fact, it has achieved impressive accomplishments in the sphere of water sector, among others desalination, regular high quality water supply, one of the highest worldwide, one of the highest percentage of returned reclaimed water, low water decrease. The pupils also faced the issue of preventing water contamination. The students presented the pupils a sample of a city with plants and houses. They poured spices as pepper and turmeric on the sample which simulated the pollutants emitted from the transportation, industry and the energy production processes in order to illustrate to the students how factories and houses contaminate the environment. Afterwards, they did so with water on the sample so as to simulate and exemplify how rain penetrates the soil altogether with the pollutants contaminating the ground water which serve as drinking water. The students together with the pupils built a filter (based on active coal) and demonstrated that "cleaning" water is a long and difficult process as opposed to contaminating it which is a very fast one.

\subsection{Waste and Recycling}

Another problem in Israel is a solid trash. The Ministry of the Environmental Protection works to reduce the amount of waste accumulating at landfills. One the best approaches to reduce waste amount is a recycling process, in which appropriate materials are being removed from the waste stream and used as raw materials for creating new materials. Most recycling in Israel is carried out in sorting and separation plants. A waste and recycling group of students and pupils had a goal to raise awareness about the sad situation existing in the country on waste issues with emphasis on the recycling process as the best solution, which has been found so far to the problem. During the course of the activity, the pupils prepared a page of newspaper scraps and turned an old tire into an armchair. 


\subsection{Soil Contamination}

The group responsible for this topic explained the pupils layered structure of the soil. The pupils built a sample of (Pedon $=$ Soil Profile) and discussed the overall impact of soil pollution, the agriculture, ecology and so on. The pupils were challenged to try to sprout beans on a fruitful ground and one on a contaminated soil (Figure 3). The results were conclusive. They were presented to the pupils' parents and siblings.

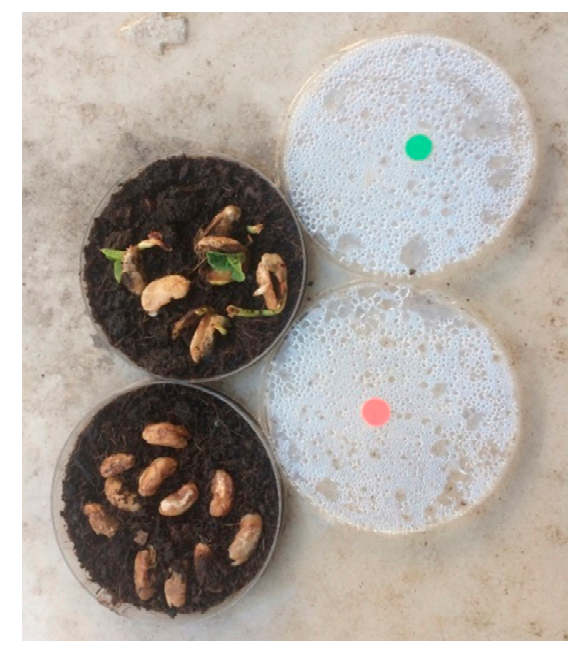

(a)

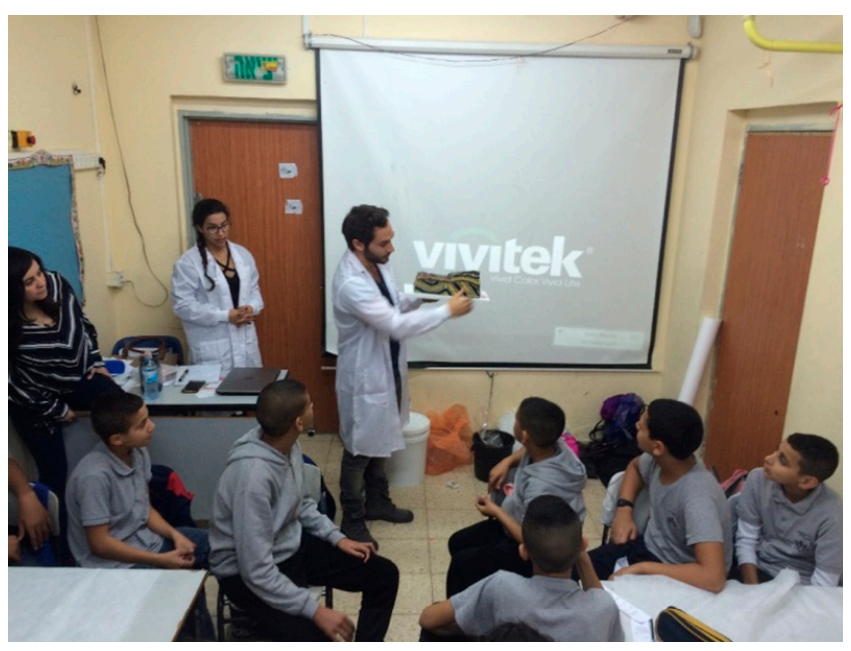

(b)

Figure 3. (a) An experiment the "soil pollution group" was asked to carry out at home sprouting beans on a fruitful ground as opposed to a contaminated soil; (b) Explains the pupils the layered structure of the soil with the help of a sample.

\section{Social Aspects}

In the last decades, there is an effort to meet Jews and Arabs (Israeli citizens), Jewish-Palestinian meeting and to perform joint projects. Schools and communities are making an effort to resist cultural and political differences to discuss them and propose strategies for coping and bridging gaps. The environment is one of the most prominent areas of discussion and so are the meetings and joint projects between Jews and Arabs. This is because both Jews and Arabs have the same limited, natural resources. They drink the same water, nurture the same soil, and breathe the same polluted air. The existing environmental situation is a good basis for a real, relevant and meaningful discussion and the understanding that environmental issues can be addressed regardless of the political conflict. Raising awareness, the treatment and involvement in the shared environment will be beneficial for both groups in addition to playing a common role in the environmental arena which can serve as a point of reference for discussion and action for the resolution of cultural and political matters and others. Environmental education and environmental activism have become favorite fields of collaboration between communities [19]. The students in the course "Green Ambassador" had to deal with a great deal of knowledge in vast environmental fields and the need to make it accessible to children. The students were also exposed to Arab society, overcame prejudices and they also had to overcome a linguistic barrier $[4,19]$. The students have been Hebrew speakers and the pupils, Arab speakers. In The State of Israel, learning the Arabic written language is required in grades seven to nine since the study of Arabic as a foreign language is an inseparable part of the Ministry of Education curriculum. Arabic is the second official language in Israel alongside Hebrew, although the legal status is not necessarily expressed in everyday practices [18]. Hebrew taught in Arab schools is not a spoken language but a literary language which makes it impossible to speak on a daily basis and the method of study deals with grammar rather than in actual Hebrew conversation. This is not only 
a lack of knowledge of Hebrew but also a cultural gap that is expressed in a lack of familiarity with the Israeli mentality: language in its broadest sense includes Jewish culture and mentality- Israeli which is often in turmoil with Arab culture and values. Beyond the knowledge gap there is also a problem of self-confidence. The use of language in practice, in the usual way in the Jewish society, for example, to speak with self-confidence and with a sense of self-worth, require an understanding of Israeli Jewish culture in addition to knowledge of the language. Pupils, who are fluent in Hebrew, sometimes are afraid to talk: many times pupils find it difficult to express themselves fully and clearly. In addition to these issues, accent is sometimes an obstacle. In order to make it easier for the pupils with the challenge of bilingual learning, the students conducted lessons with little text and used a lot of images, animations, pictures and experiments. Create a positive and inviting environment in the classroom $[20,21]$.

\section{Results}

\section{Efficiency}

Throughout the whole process efficiency tests were taken. Every meeting the pupils $(n=164)$ were asked to answer a questionnaire related to issues learnt in class. In the beginning of the activity an opening questionnaire was passed on. The purpose was to know what the basic knowledge level of the pupils was (before activity). At the end of the activity a final questionnaire was delivered which indicated the progress and the knowledge acquired as a result of the activity. The questionnaire was presented to the pupils as a trivia game program. The students statistically analyzed the pupils' answers of both the opening and final questionnaires in order to see the difference in the pupils' knowledge throughout the course (Figure 4). In the opening questionnaires there were only 35\% correct responses, out of the total number of pupils, while in the final questionnaires approximately $83 \%$ were correct.

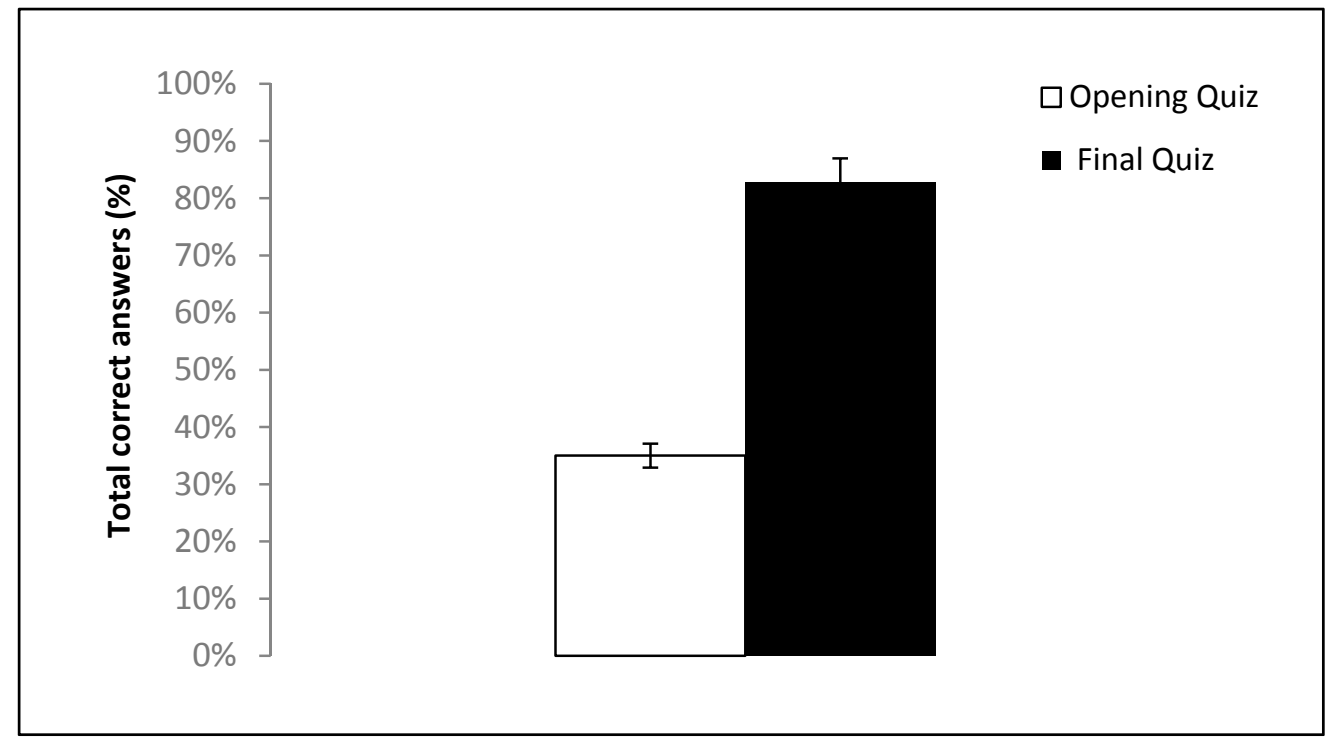

Figure 4. Total correct answers in the opening and final questionnaires.

The students checked the distribution of the responses of the opening and final questionnaires. It can be seen (Figure 5) that in the opening questionnaire there has been made a choice of various, possible answers (large scattering). In the final questionnaire, the pupils showed that they had an experience and were in a learning process. In question 4 , for example, in which the pupils were asked "what is the geothermal energy?", in the opening questionnaires, only 35\% answered correctly that this is the energy obtained from the heat of the earth $(\boldsymbol{\Lambda})$. About $20 \%$ from the pupils thought it was 
hydrogen energy $(\bullet)$, nobody thought it was wind energy $(\bullet)$, and about $45 \%$ thought it was the energy from the sea waves ( $\boldsymbol{\square})$. In the final questionnaires, after the pupils learned about the, geothermal energy, 75\% have chosen the correct answer.

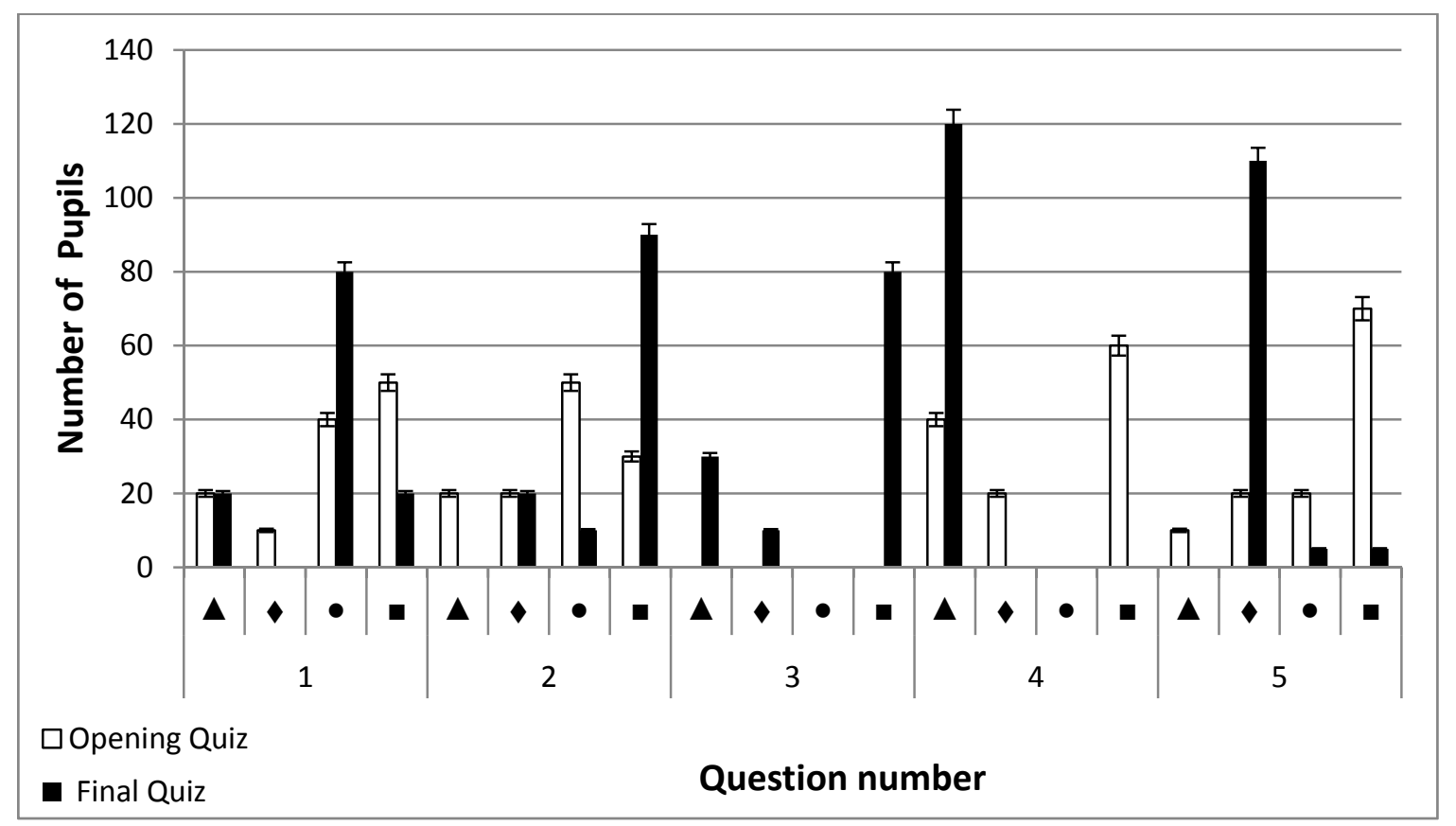

Figure 5. The distribution of the responses in the opening and the final questionnaires.

When the students measured the response time in the beginning of the quiz versus the end (after the end of the activity) it turned out that it shortened significantly due to the knowledge and confidence acquired which was resulting from the activity.

Figure 6 shows that the time response to the questions in the opening questionnaire was between 21 and 68 s. In the final questionnaire, however, the time response has been shortened from several seconds up to 18 , due to the confidence the pupils have felt with mastering the material studied. It seems that the pupils have learned and understood the subjects that were explained to them in the activity. The pupils felt confident in their knowledge and therefore answered faster than they answered on opening questionnaires. And it has to be noticed that about $83 \%$ of them answered correctly on the final questionnaires (Figure 4). 


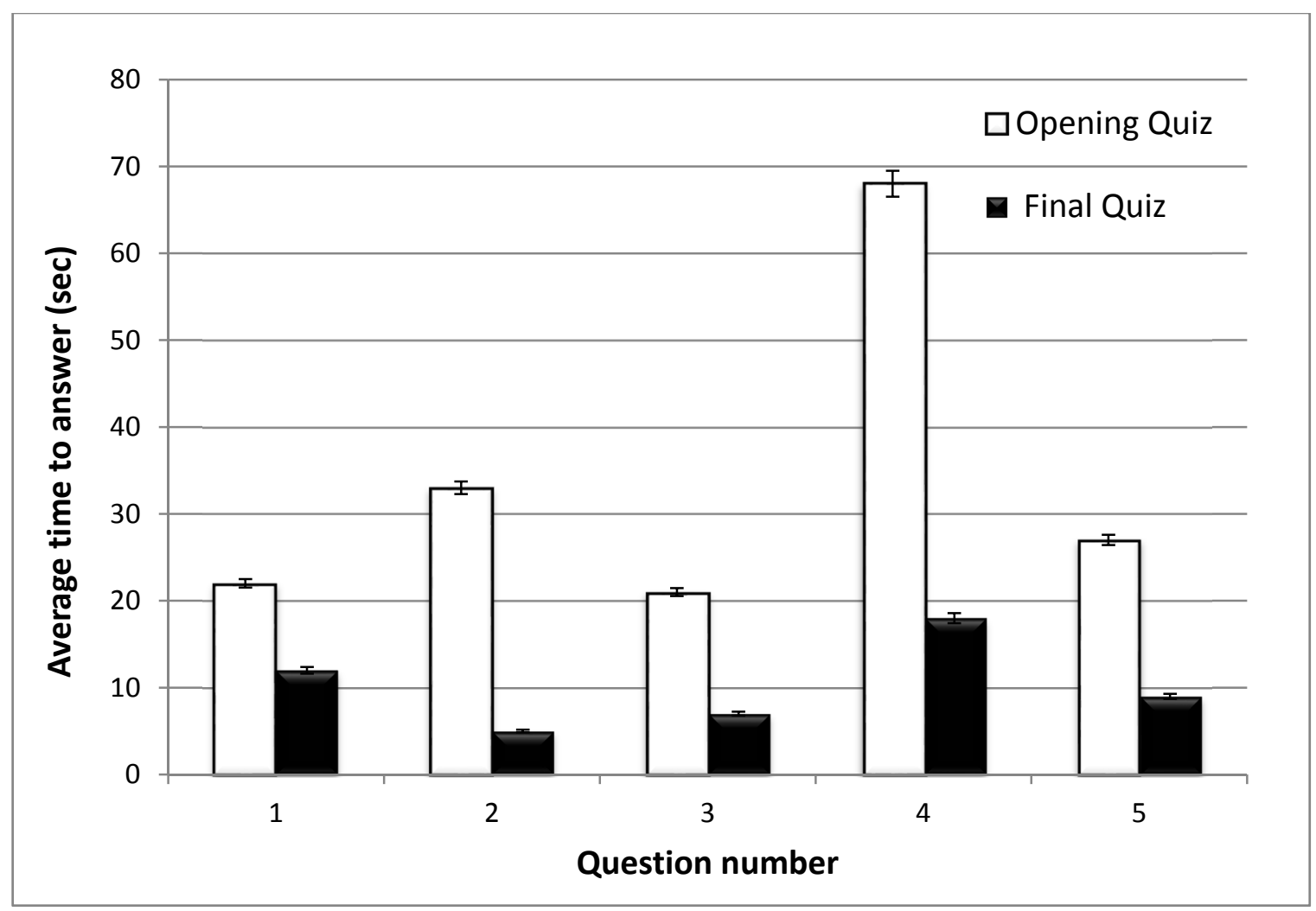

Figure 6. Analyzing the duration of the average response of the opening and the final questionnaires.

\section{Conclusions}

In the "Green Ambassador" in the Community course, which involves action, participating students engaged in an experiential learning process, that included creating a dialogue and cross-fertilization between what was being studied in the classroom and reality. Based on the results, at the beginning of the lesson, pupils hesitated and took a long time before picking an answer. This hesitation can be explained by the fact that the pupils did not have extensive knowledge about the subject. On the other hand, on the exit test, there was a significant improvement as pupils quickly selected the correct answer, demonstrating their improved knowledge of Renewable Energy, Ecology and Environment.

Author Contributions: H.F., I.B., Y.S. and Y.E. conceived and designed the experiments; H.F. and T.S. performed the experiments; H.F. and T.S. analyzed the data; H.F, T.S. and Y.E. wrote the paper.

Acknowledgments: We would like to thank the Higher Education Council for budgeting and supporting this course. To the Social Involvement Unit, thanks for their support and for allowing such a course to take place at the HIT, as well as helping us contribute to society and future generations. Last but not least, we want to thank "Alomaria" School for the opportunity to take a part in the next generation of education for a better and cleaner environment.

Conflicts of Interest: The authors declare no conflict of interest.

\section{References}

1. Olneck, M. Can multicultural education change what counts as cultural capital? Am. Educ. Res. J. 2000, 37, 317-348. [CrossRef]

2. Bilgen, S.; Kaygusuz, K.; Sari, A. Renewable energy for a clean and sustainable future. Energy Sources Part A Recovery Util. Environ. Effects 2004, 26, 1119-1129. [CrossRef]

3. Friman, H.; Matsliah, N.; Beck, Y. Renewable energy lab at the Faculty of Electrical Engineering. In Proceedings of the 10th Annual International Technology, Education and Development Conference (INTED2016), Valencia, Spain, 7-9 March 2016; pp. 2311-2318. 
4. Al-Haj, M. Higher education among the Arabs in Israel: Formal policy between empowerment and control. High. Educ. Policy 2003, 16, 351-368. [CrossRef]

5. Arar, K. Israeli education policy since 1948 and the state of Arab education in Israel. Ital. J. Sociol. Educ. 2012, 4, 113-141.

6. Reddan, G.; Rauchle, M. Student perceptions of the value of career development learning to a work-integrated learning course in Exercise Science. Aust. J. Career Dev. 2012, 21, 38-48. [CrossRef]

7. Walker, J.D.; Jorn, L. 21st Century Students: Technology Survey; Office of Information Technology, University of Minnesota Twin Cities: Minneapolis, MN, USA, 2009.

8. Fink, L.D. Creating Significant Learning Experiences: An Integrated Approach to Designing College Courses; Jossey-Bass: San Francisco, CA, USA, 2003.

9. Price, C. Motivating Students: From Pathetic to Inspired. Faculty Focus Online Seminar. 2013. Available online: http:/ / / www.facultyfocus.com/seminars (accessed on 16 September 2013).

10. Juli-Anna, A.; Lydia, K. Multicultural literature and the use of literature in multicultural education in Finland. J. Int. Child. Lit. 2013, 51, 39-50.

11. West, M.R.; Kraft, M.A.; Finn, A.S.; Martin, R.E.; Duckworth, A.L.; Gabrieli, C.F.O.; Gabrieli, J.D.E. Promise and paradox: Measuring students' non-cognitive skills and the impact of schooling. Educ. Eval. Policy Anal. 2016, 38, 148-170. [CrossRef]

12. Shulman, L.S.; Tamir, P. Second Handbook of Research on Teaching; Travers, R.M.W., Ed.; Rand McNally College Publ. Co.: Chicago, IL, USA, 1973; pp. 1098-1148.

13. Brown, D.E. Using examples and analogies to remediate misconceptions in physics: Factors influencing conceptual change. J. Res. Sci. Teach. 1992, 29, 17-34. [CrossRef]

14. Osborne, J.; Dillon, J. Science Education in Europe: Critical Reflections; Nuffield Foundation: London, UK, 2008.

15. Bourdieu, P. The forms of capital. In Handbook of Theory and Research for the Sociology of Education; Richardson, J., Ed.; Greenwood: New York, NY, USA, 1986; pp. 241-258.

16. Yager, R.E. Constructivism and the learning of science. In Learning Science in the Schools: Research Reforming Practice; Glynn, S.M., Duit, R., Eds.; Erlbaum: Mahwah, NJ, USA, 1995; pp. 35-38.

17. Friman, H. The Ecological Garden for environmental education through experiential tools. Negev Dead Sea Arava Stud. 2016, 8, 139-146.

18. Kaltschmitt, M.; Streicher, W.; Wiese, A. Renewable Energy Technology, and Environmen; Springer: Berlin/Heidelberg, Germany, 2007.

19. Jabareen, Y.; Agbaria, A. Education on Hold: Israeli Government Policy and Civil Society Initiatives to Improve Arab Education in Israel; The Arab Center for Law and Policy \& The Arab Minority Rights Clinic, Faculty of Law, University of Haifa: Haifa, Israel, 2011; Available online: http:/ / iataskforce.org/sites/default/files / resource/resource-223.pdf (accessed on 15 April 2018).

20. Friman, H.; Halabi, I.; Ochayon, A.; Banner, I.; Shalom-Tuchin, B.; Einav, Y. Environmental education for the community. Int. J. Environ. Sci. 2017, 2, 166-170.

21. Dornyei, Z. Creating a Motivating Classroom Environment. In International Handbook of English Language Teaching; Cummins, J., Davison, C., Eds.; Springer: New York, NY, USA, 2007; pp. 719-731.

(c) 2018 by the authors. Licensee MDPI, Basel, Switzerland. This article is an open access article distributed under the terms and conditions of the Creative Commons Attribution (CC BY) license (http://creativecommons.org/licenses/by/4.0/). 